\title{
CORRIGENDUM
}

\section{Summertime climate response to mountain pine beetle disturbance in British Columbia}

\section{H. Maness, P. J. Kushner and I. Fung}

Nature Geoscience 6, 65-70 (2013); published online 25 November 2012; corrected after print 27 June 2014.

In the version of this Article originally published, the $f_{\text {live }}$ values in Fig. $4 \mathrm{c}$ should have been listed in the reverse order, with ' $0.0-0.1^{\prime}$ corresponding to the black curve and ' $0.9-1.0$ ' to the red curve, as shown below. This error has now been corrected in all online versions of the Article.

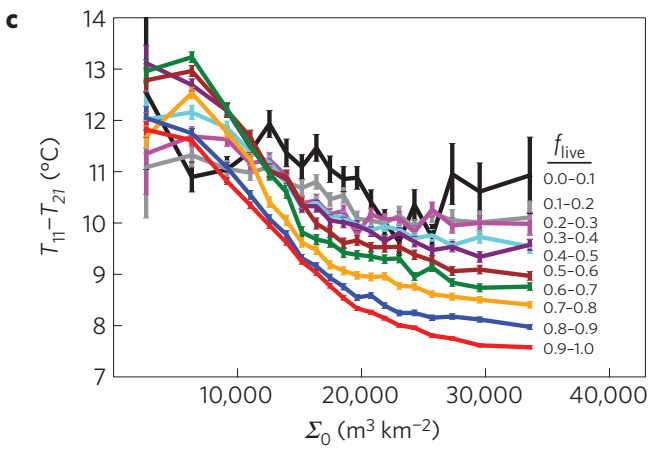

